\title{
A SIMPLE ENERGY BALANCE MODEL OF ICE SEGREGATION
}

S. Outcalt

Department of Geography, University of Michigan, Ann Arbor, Michigan 48109, U.S.A.

\section{ABSTRACT}

Step functions of normal frost front advance in dry and wet soils are reviewed and used to introduce the geometry of the soil frost system. An energy balance equation at the initiation of ice lens growth is developed using simple physical assumptions. This model is then employed to simulate the effects of varied surface temperature depression and water table depth on the timing, position and rate of ice lens growth. Lowering the water table delays the onset of segregation but the Initial heave rates are all above half a meter per year in the region examined.

\section{INTRODUCTION}

Step functions in the surface temperature regime have been used to analyze the rate of penetration of a freezing front in soils. These solutions require a knowledge of the thermal conductivities of the unfrozen and frozen soils $\left(K_{u}, K_{f}\right)$ the volumetric heat capacity of these materials $\left(C_{u}, C_{f}\right)$ and the surface temperature $\left(T_{a}\right)$. The first step equation to be considered is that of Terzaghi (1952). The material is assumed to be at $0^{\circ} \mathrm{C}$ at all depths when the surface temperature is lowered to $\mathrm{T}_{\mathrm{a}}$ for all future time. The depth of frost $\left(z_{f}\right)$ in this material, which contains no water, and thus is free of latent heat effects, is shown as equation 1 where no subscripts are employed in the thermal property notations as the thermal properties are assumed to be the same in frozen and unfrozen states. The time length since the initiation of the thermal disturbance is $(t)$ in compatible units.

$\mathrm{Z}_{\mathrm{f}}=\sqrt{12(\mathrm{~K} / \mathrm{C}) \mathrm{t}} \quad$ Terzaghi Equation

Note that the depth of penetration in the "dry case" is only a function of the thermal. diffusivity $(\mathrm{K} / \mathrm{C})$ and time being independent of the magnitude of the thermal disturbance.

Terzaghi (1952) modified the equation developed by Stefan (1891) for soils with the addition of the effects of an assumed saturated pore space $\left(X_{p}\right)$ in combination with latent heat of fusion ( $L$ ) and the energy withdrawal necessary to undercool the frozen layer. This equation is shown as equation 2 .

$\mathrm{Z}_{\mathrm{f}}=\sqrt{\left(2 \mathrm{~K}_{\mathrm{f}}\left|\mathrm{T}_{\mathrm{a}}\right| \mathrm{t}\right) /\left(\mathrm{X}_{\mathrm{p}} \mathrm{L}+\mathrm{C}_{\mathrm{f}}\left(\left|\mathrm{T}_{\mathrm{a}}\right| / 2\right)\right)}$

Stefan Equation

Note that in this case the depth of penetration is dependent upon both the magnitude and duration of the surface thermal disturbance. In this solution the Impact of the heat flow from the unfrozen zone is neglected to achieve a simple algebraic solution. However the Neumann Formulation which requires a numerical solution includes heat flow in the unfrozen zone (Jumikis (1966)). It should be noted that the soil heave is limited to $\left[\left(\frac{\rho_{w}}{\rho_{i}}\right)-\rho_{w}\right] x_{p} Z_{f}$ in this system where $\left(\rho_{w} / \rho_{i}\right)$ is the ratio of water to ice density.

Lastly, consider segregation ice freezing in which the heave is not theoretically bounded when it occurs over a stable water 
table. The geometry of this system is abstracted in Fig. 1. Arakawa (1966) demonstrated that a segregation efficiency index could be computed based on the heat and water flux rates in the soil. Here we use additional notation $Z$ and $H$ for the hydraulic conductivity of soil water and soil water potential. The notation employed is listed as an appendix.

The formulation of the Arakawa Model is as follows.

$Q_{f}=K_{f}\left(\frac{\partial T}{\partial Z}\right)_{f} \begin{aligned} & \text { heat flow in frozen zone } \\ & \text { toward surface }\end{aligned}$

$Q_{u}=K_{u}\left(\frac{\partial T}{\partial Z}\right)$ heat flow in unfrozen

$Q_{W}=L K\left(\frac{\partial H}{\partial Z}\right)$ heat necessary to freeze water arriving in the freezing region

$Q_{\uparrow}=Q_{f}-Q_{u}$ total heat loss

if $Q_{\uparrow}>Q_{W}$ normal freezing

If $Q_{\uparrow} \leq Q_{W}$ segregation freezing

It is also possible to set up a segregation index (E).

$E=Q_{W} / Q_{\uparrow} \quad \begin{aligned} & \text { If } E \geq 1 ., \text { ice lensing } \\ & \text { will occur. }\end{aligned}$

In review there are three models for increasingly complex modes of soil frost; these are abstracted in Table 1 . The Terzaghi and Stefan solutions are used in civil engineering practice. It will be recalled that $\left|\mathrm{T}_{a}\right| \cdot t$ in the Stefan solution can be expressed as the frost degree-day integral. The Arakawa Model has been used as a conceptual device for setting up computer models of coupled flow with rather awesome complexity (Guymon and Luthin (1974), Harlan (1975)). However numerical models of coupled flow become extremely sensitive to iteration frequency when vapor transport is added to heat and water flux (Outcalt (1979)). Earlier Palmer (1967) produced a simple analytical solution to the ice lensing problem. The intention of this paper is to produce another extremely simple model of the process using equations 3.5 and 3.6 .

THE STRUCTURE OF THE SIMPLE MODEL

The energy balance geometry sketched in Fig. 1 is somewhat similar to the Stefan Model. However, water flux is added and the equation is set to represent the equilibrium that must exist when ice segregation begins. If equilibrium is a reasonable assumption then the duration of time necessary for the freezing region to deepen to the level at which segregation occurs can be estimated by solving the Stefan equation for time. The heave rate could then be expressed by equation 4.

$\mathrm{dh} / \mathrm{dt}=\left(\rho_{W} / \rho_{i}\right) \ldots \frac{\mathrm{H}_{W}-\mathrm{H}_{\mathrm{f}}}{\mathrm{Z}_{W}-\mathrm{Z}_{\mathrm{f}}} \quad$ heave rate

The problem is now to specify the state variables $\left(\mathrm{T}_{\mathrm{f}}, \mathrm{H}_{\mathrm{f}}\right)$ and the system parameter $\ldots$ (see Appendix). A parsimonious and admittedly expedient approach is to assume that segregation occurs at some slightly subfreezing temperature $\left(-0.1^{\circ} \mathrm{C}\right)$. If there is a constant relationship $(\partial \mathrm{H} / \partial \mathrm{T}=12.43 \mathrm{x}$ $\left.10^{3} \mathrm{~cm} . /{ }^{\circ} \mathrm{C}\right)$ below $0^{\circ} \mathrm{C}$ then $\mathrm{H}(\mathrm{T})$ and $\mathrm{K}(\mathrm{H})$ can be specified. Then $\mathrm{H}_{f}$ is $-1243 . \mathrm{cm} \cdot \mathrm{H}_{2} \mathrm{O}$ and the value of $\mathrm{K}\left(\mathrm{H}\left(-.05^{\circ} \mathrm{C}\right)\right)$ is representative of the value of unsaturated hydraulic conductivity in the region where water is moving toward the segregation region (at $-0.1^{\circ} \mathrm{C}$ ) through the freezing region. We used available data for a sandy loam in the calculations ( $\mathrm{K}=1 \cdot \mathrm{x} 10^{-7} \mathrm{~cm} \cdot \mathrm{sec}^{-1}$ ). It is assumed further that the water potential gradient is linear between the water table and the "f level." In this simple model, again in the interest of parsimony, no adjustment was made for gravity potential as that involves assumptions concerning the time dependent evolution of the potential gradients which 


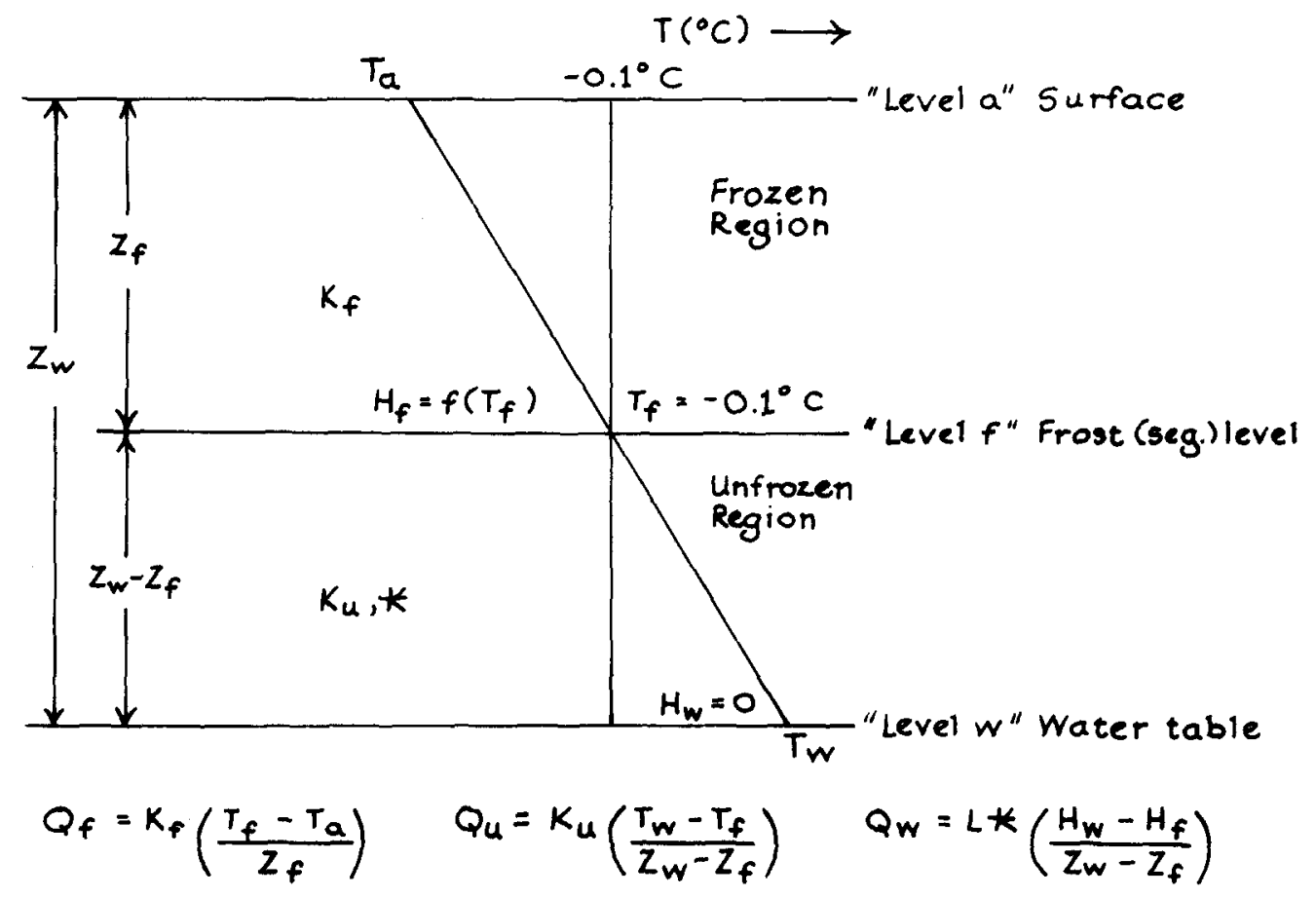

Fig. 1. Geometry of Segregation Ice Formation System at the Onset of Lens Growth $Q_{f}-Q_{u}-Q_{w}=0.0$ (see text)

Tabie 1. Summary of Frost Models

\begin{tabular}{|c|c|c|c|}
\hline $\begin{array}{l}\text { Frost } \\
\text { Type }\end{array}$ & $\begin{array}{c}\text { Step Function } \\
\text { Model }\end{array}$ & $\begin{array}{l}\text { Soil } \\
\text { Heave }\end{array}$ & $\begin{array}{c}\text { Depth } \\
\text { of Frost } \\
\text { a function of }\end{array}$ \\
\hline Dry Frost & Terzaghi & None & $K_{f}, C_{f}, t$ \\
\hline Wet Frost & Stefan & {$\left[\left(\rho_{\mathrm{w}} / \rho_{\mathrm{i}}\right)-\rho_{\mathrm{w}}\right] \mathrm{X}_{\mathrm{p}} \mathrm{z}_{\mathrm{f}}$} & $\mathrm{K}_{\mathrm{f}}, \mathrm{C}_{\mathrm{f}_{\mathrm{T}}, \mathrm{t}}$ \\
\hline $\begin{array}{l}\text { Segregation } \\
\text { Frost }\end{array}$ & Arakawa & $\begin{array}{c}\text { No theoretical } \\
\text { limit }\end{array}$ & $\begin{array}{l}\text { Initially as } \\
\text { with wet frost } \\
\text { then terminated } \\
\text { by segregation }\end{array}$ \\
\hline
\end{tabular}


may or may not be in hydraulic contact with the water at the $-0.1^{\circ} \mathrm{C}$ isotherm especially during the initial stages of frost advance toward a deep water table. The bulk thermal conductivities of the frozen and unfrozen regions were calculated on the basis of a porosity of $38 \%$, again assuming saturation and total frost or thaw in these zones. These assumptions while being extremely liberal permit the formulation of the equilibrium expression in a nice transcendental form reminiscent of the Neumann solution.

$\mathrm{K}_{\mathrm{f}}\left(\frac{\mathrm{T}_{\mathrm{f}}-\mathrm{T}_{\mathrm{a}}}{\mathrm{Z}_{\mathrm{f}}}\right)-\mathrm{K}_{\mathrm{u}}\left(\frac{\mathrm{T}_{\mathrm{w}}-\mathrm{T}_{\mathrm{f}}}{\mathrm{Z}_{\mathrm{W}}-\mathrm{Z}_{\mathrm{f}}}\right)-\mathrm{LK}\left(\frac{\mathrm{H}_{\mathrm{w}}-\mathrm{H}_{\mathrm{f}}}{\mathrm{Z}_{\mathrm{w}}-\mathrm{Z}_{\mathrm{f}}}\right)=\mathrm{E}\left(\mathrm{Z}_{\mathrm{f}}\right)$

where $f\left(z_{f}\right) \rightarrow 0.0$ by the Newton method. Convergence to within $1 \times 10^{-10} \mathrm{cal} . \mathrm{cm} .^{-2}$ sec. ${ }^{-1}$ was achieved in under ten iterations using initial values for $Z_{f}$ of $(0.2 \mathrm{~cm}$.$) and$ $\left(z_{w}-0.2 \mathrm{~cm}.\right)$.

\section{RESULTS OF SIMULATION TESTS}

The behavior of this rather crude analog was analyzed by setting the temperature of the water table to $+1^{\circ} \mathrm{C}$ and varying the water table depth over the range of $10-100 \mathrm{~cm}$. in $10 \mathrm{~cm}$. steps and the surface temperature over the range of -2 to $-20^{\circ} \mathrm{C}$ in $2^{\circ} \mathrm{C}$ steps. This process yielded three matrices showing distance from the water table to the lens base distance (cm.), time at which segregation began (days) and heave rate due to segregation (mn./day). The initial heave due to normal in-situ frost is $\left[\left(\frac{\rho_{W}}{\rho_{1}}\right)-\rho_{W}\right] x_{p} Z_{E} \cdot$ The matrices produced by these simulations are presented in Table 2. The following genera1ization can be drawn about model performance from these results.

First the unfrozen thickness at segregation decreases with lowered surface temperature at each water table depth. Therefore normal frost depth decreases with increasing surface temperature. Segregation is thus delayed by lowered surface temperature until the frozen zone temperature gradient is reduced and the water potential gradient increases as normal frost advances. The length of time until the start of segregation is influenced by both the magnitude of the temperature depression at the surface and the depth of normal freezing (equation 2). These two factors interact in such a way to produce a maximum time to segregation at a temperature depression of approximately $-6^{\circ} \mathrm{C}$ at all water table depths tested. At lowered surface temperatures the magnitude of the temperature depression overrides frost depth effects to reduce the time at which segregation begins. At all water table depths the increased surface temperature depression increases the heave rate. The largest heave rates occur with large temperature depressions. However, it should be noted that over long periods of time even the lowest heave rate $(1.67 \mathrm{~mm}$./day) is equivalent to $.5 \mathrm{~m} . / \mathrm{yr}$. Increased water table depths delay the onset of segregation but eventually substantial heave rates are produced.

\section{CONCLUSIONS}

The object of this paper is first to describe the energy budget model for ice lensing in the most simple manner possible. In the process a considerable amount of physical detail was sacrificed on the "altar of parsimony." This lost detall may be significant.

However given laboratory tests it may be possible to calculate values for the "apparent hydraulic conductivity" and utilize the solution methods described here for engineering calculations in much the same manner as the Stefan solution is now employed. 
Table 2. Simulation Matrices (see text)

\begin{tabular}{|c|c|c|c|c|c|c|c|c|c|c|}
\hline & \multicolumn{10}{|c|}{ Surface Temperature $\left({ }^{\circ} \mathrm{C}\right)$} \\
\hline & -2 & -4 & -6 & -8 & -10 & -12 & -14 & -16 & -18 & -20 \\
\hline 10 & 7.31 & 5.69 & 4.66 & 3.94 & 3.41 & 3.01 & 2.69 & 2.42 & 2.20 & 2.02 \\
\hline 20 & 14.61 & 11.33 & 9.32 & 7.88 & 6.83 & 6.48 & 5.37 & 4.85 & 4.41 & 4.04 \\
\hline 30 & 21.92 & 17.07 & 13.97 & 11.82 & 10.24 & 9.01 & 8.05 & 7.27 & 6.61 & 6.06 \\
\hline 40 & 29.22 & 22.76 & 18.63 & 15.76 & 13.65 & 12.03 & 10.74 & 9.69 & 8.82 & 8.08 \\
\hline 50 & 36.53 & 23.45 & 23.29 & 19.70 & 17.06 & 15.04 & 13.43 & 12.12 & 11.03 & 10.10 \\
\hline 60 & 43.84 & 34.14 & 27.95 & 23.62 & 20.47 & 18.04 & 16.11 & 14.54 & 13.23 & 12.12 \\
\hline 70 & 51.14 & 39.83 & 32.61 & 27.59 & 23.89 & 21.05 & 18.80 & 16.96 & 15.43 & 14.14 \\
\hline 80 & 58.45 & 45.52 & 37.27 & 31.53 & 27.30 & 24.07 & 21.48 & 19.39 & 17.64 & 16.15 \\
\hline 90 & 65.75 & 51.21 & 41.93 & 35.46 & 30.71 & 27.06 & 24.16 & 21.81 & 19.84 & 18.17 \\
\hline 100 & 73.06 & 56.90 & 46.59 & 39.40 & 34.13 & 30.07 & 26.35 & 24.25 & 22.05 & 20.20 \\
\hline
\end{tabular}

THICKNESS OF UNFROZEN ZONE AT SEGREGATION (CM.)

\begin{tabular}{|c|c|c|c|c|c|c|c|c|c|c|}
\hline & \multicolumn{10}{|c|}{ Surface Temperature $\left({ }^{\circ} \mathrm{C}\right)$} \\
\hline & -2 & -4 & -6 & -8 & -10 & -12 & -14 & -16 & -18 & -20 \\
\hline 10 & 0.10 & 0.13 & 0.14 & 0.13 & 0.13 & 0.12 & 0.12 & 0.11 & 0.11 & 0.10 \\
\hline 20 & 0.41 & 0.53 & 0.55 & 0.54 & 0.51 & 0.46 & 0.47 & 0.44 & 0.42 & 0.41 \\
\hline 30 & 0.91 & 1.19 & 1.23 & 0.21 & 1.16 & 0.11 & 1.05 & 1.00 & 0.95 & 0.91 \\
\hline 40 & 1.62 & 2.11 & 2.19 & 2.15 & 2.06 & 1.96 & 1.87 & 1.78 & 1.69 & 1.62 \\
\hline 50 & 2.53 & 3.29 & 3.42 & 3.35 & 3.22 & 3.07 & 2.91 & 2.78 & 2.65 & 2.53 \\
\hline 60 & 3.65 & 4.74 & 4.93 & 4.84 & 4.63 & 4.41 & 4.20 & 4.00 & 3.81 & 3.65 \\
\hline 70 & 4.97 & 6.45 & 6.71 & 6.57 & 6.31 & 6.01 & 5.72 & 5.44 & 5.19 & 4.96 \\
\hline 3 80 & 6.49 & 8.43 & 8.77 & 8.58 & 8.24 & 7.84 & 7.46 & 7.11 & 6.78 & 6.48 \\
\hline 90 & 8.21 & 10.67 & 11.09 & 10.87 & 10.42 & 9.93 & 9.45 & 8.99 & 8.58 & 8.21 \\
\hline 100 & 10.14 & 13.17 & 13.69 & 13.41 & 12.87 & 12.26 & 11.67 & 11.10 & 10.59 & 10.13 \\
\hline
\end{tabular}




\begin{tabular}{|c|c|c|c|c|c|c|c|c|c|c|}
\hline & & & & Sur & ace Tem & erature & $\left({ }^{\circ} \mathrm{C}\right)$ & & & \\
\hline & -2 & -4 & -6 & -8 & -10 & -12 & -14 & -16 & -18 & -20 \\
\hline 10 & 15.98 & 20.51 & 25.06 & 29.62 & 34.20 & 38.83 & 43.39 & 48.18 & 52.95 & 57.76 \\
\hline 20 & 7.99 & 10.26 & 12.53 & 14.81 & 17.03 & 18.00 & 21.73 & 24.09 & 26.48 & 28.90 \\
\hline 30 & 5.33 & 6.84 & 8.35 & 9.87 & 11.40 & 12.96 & 14.49 & 16.06 & 17.65 & 19.27 \\
\hline 40 & 3.99 & 5.13 & 6.27 & 7.41 & 8.55 & 9.71 & 10.37 & 12.05 & 13.24 & 14.45 \\
\hline 50 & 3.20 & 4.10 & 5.01 & 5.92 & 6.84 & 7.76 & 8.69 & 9.64 & 10.59 & 11.56 \\
\hline 60 & 2.66 & 3.42 & 4.18 & 4.94 & 5.70 & 6.47 & 7.25 & 8.03 & 8.82 & 9.63 \\
\hline 70 & 2.23 & 2.93 & 3.58 & 4.23 & 4.89 & 5.55 & 6.21 & 6.88 & 7.56 & 8.26 \\
\hline 80 & 2.00 & 2.56 & 3.13 & 3.70 & 4.23 & 4.85 & 5.43 & 6.02 & 6.62 & 7.23 \\
\hline 90 & 1.73 & 2.23 & 2.78 & 3.29 & 3.80 & 4.31 & 4.83 & 5.35 & 5.88 & 6.42 \\
\hline 100 & 1.60 & 2.05 & 2.51 & 2.96 & 3.42 & 3.88 & 4.35 & 4.81 & 5.29 & 5.73 \\
\hline
\end{tabular}

INITIAL HEAVE RATE AT SEGREGATION (MM./DAY)

\section{ACKNOWLEDGMENTS}

This research was carried out as part of a joint research project between Pennsylvania State University and The University of Michigan entitled Modeling Physical and Thermal Disturbance in Permafrost Terrain of Northern Alaska. The work was sponsored by the office of Polar Programs, U.S. National Science Found ation, Washington, D.C. (NSF-TPSU-IM 22206-131).

The idea of producing this simple solution is the result of discussions on ice lensing theory held at the U.S. Army Cold Regions Research and Engineering Laboratory during January 1977. This workshop was organized by Dr. Shunsuke Takagi of CRREL. The author is indebted to Dr. Gary Guymon of the Irvine Campus of the University of California for his many helpful comments on this topic.

\section{REFERENCES}

Arakawa, K. (1966), Theoretical studies of ice segregation in soils, Journal of Glaciology, 6:44, 255-260.

Guymon, G. and J.N. Luthin (1974), A coupled heat and moisture transport mode1 for Arctic soils, Water Resources Research, $10: 5,995-1003$.

Harlan, R.L. (1973), Analysis of coupled heat-fluid transport in partially frozen soil, Water Resources Research, 9:5, 1314-1323.

Jumikis, A.R. (1966), Thermal Soil Mechanics, Rutgers University Press.

Outcalt, S. (1979), The effect of iteration frequency in a numerical model of near surface ice segregation, Engineering Geology (in press).

Palmer, A.C. (1967), Ice lensing, thermal diffusion and water migration in freezing soils, Journal of Glaciology, 6:47, 681694.

Stefan, J. (1891), On the theory of ice formation in the Polar Sea (in German), Ann. Physik 4, 3rd series, 269-286.

Terzaghi, K. (1952), Permafrost, Jour. Boston Soc. Civil Eng., 39:1, 319-368. 
Appendix. Notation

\begin{tabular}{|c|c|c|c|}
\hline & Notation & Units & Interpretation \\
\hline \multirow{6}{*}{$\begin{array}{l}\text { Boundary } \\
\text { Conditions } \\
\text { (const.) }\end{array}$} & $\mathrm{T}_{\mathrm{a}}$ & ${ }^{\circ} \mathrm{C}$ & surface temperature \\
\hline & $\mathrm{T}_{\mathrm{w}}$ & ${ }^{\circ} \mathrm{C}$ & $\begin{array}{l}\text { water temperature at water } \\
\text { table }\end{array}$ \\
\hline & $\mathrm{H}_{\mathrm{w}}$ & $\mathrm{cm}$ & $\begin{array}{l}\text { water potential at water } \\
\text { table }(0 .)\end{array}$ \\
\hline & $\mathrm{T}_{\mathrm{f}}$ & ${ }^{\circ} \mathrm{C}$ & $\begin{array}{l}\text { temp. where segregation } \\
\text { occurs }\left(-0.1^{\circ} \mathrm{C}\right)\end{array}$ \\
\hline & $\mathrm{H}_{\mathrm{f}}$ & $\mathrm{cm}$ & $\begin{array}{l}\text { water potential at } \\
\mathrm{T}_{\mathrm{f}}(-1243 .)\end{array}$ \\
\hline & $\mathrm{Z}_{\mathrm{w}}$ & $\mathrm{cm}$ & $\begin{array}{l}\text { distance from surface to } \\
\text { water table }\end{array}$ \\
\hline \multirow[t]{3}{*}{ Parameters } & $\mathrm{K}_{\mathrm{f}}$ & cal $\mathrm{cm}^{-1} \mathrm{sec}^{-1}{ }^{\circ} \mathrm{C}^{-1}$ & $\begin{array}{l}\text { thermal conductivity of } \\
\text { frozen region }\end{array}$ \\
\hline & $\mathrm{K}_{\mathrm{u}}$ & cal $\mathrm{cm}^{-1} \mathrm{sec}^{-1}{ }^{-1} \mathrm{C}^{-1}$ & $\begin{array}{l}\text { thermal conductivity of } \\
\text { unfrozen region }\end{array}$ \\
\hline & \# & $\mathrm{cm} \mathrm{sec}^{-1}$ & $\begin{array}{l}\text { hydraulic conductivity at } \\
-0.05^{\circ} \mathrm{C}\end{array}$ \\
\hline Variable & $Z_{F}$ & $\mathrm{~cm}$ & $\begin{array}{l}\text { distance from surface to } \\
\text { "f level" }\end{array}$ \\
\hline Const. & $\mathrm{L}$ & $\mathrm{cal} \mathrm{cm}^{-3}$ & $\begin{array}{l}\text { volumetric heat of fusion } \\
(80 .)\end{array}$ \\
\hline
\end{tabular}

